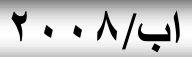

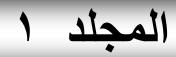

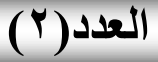 \\ مجلة علوم ذي قار
}

ISSN 1991- 8690

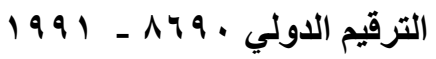

website: http://jsci.utq.edu.iq

Email: utjsci@utq.edu.iq

دراسة تأثير إضافة العامل المنشط للسطح دوداكيل بنزين سلفونات الامونيوم التوأمية على

مقاومة الأنضغاط لخلطة أسمنتية ذات المعالجة الرطبة.

ناظم عبد الجليل عبدالله

جامعة البصرة - مركز أبحاث البوليمر - قسم علوم المواد.

E-mail:Nadhim_2007@yahoo.com

الخلاصة

تم في هذه الدراسة اضافة العامل المنشط للسطح دوداكيـل بنـزين ســلفونات الامونيـوم

(Dodecyl Benzene Ammonium Sulphonate)

^^\%) إلى خلطة الاسمنت العراقي (المنتج من معمل ام قصر) لغرض دراسه خواصه. تم معالجة العينات

الجليدة باستخدام طريقة (المعالجة الرطبه Moisture Curing) و كانت جميع العينــات المحضــرة

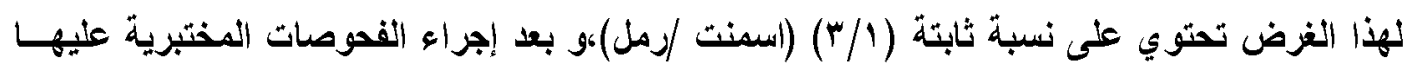
هن خلال النتائج التجريبية المستحصل تم تقييم الخلطة الاسمنتية الجليدة وعلى وجه الخصوص الخلطة

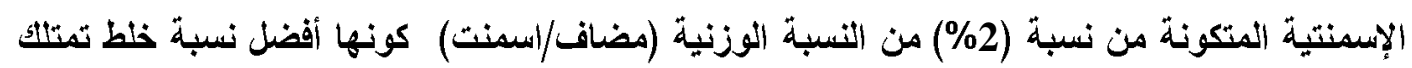

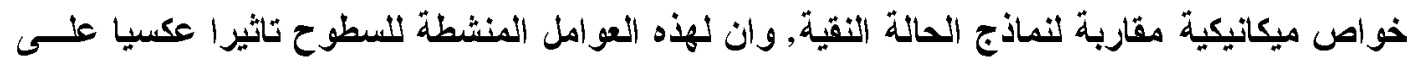

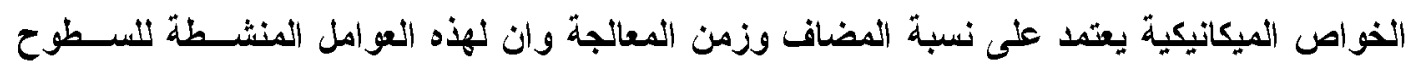

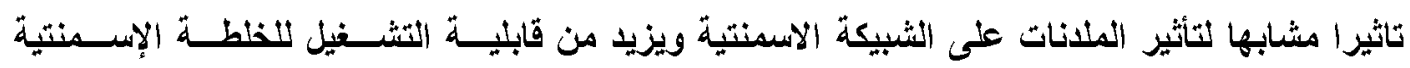

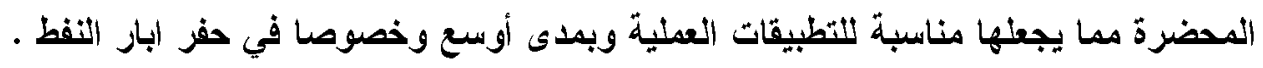




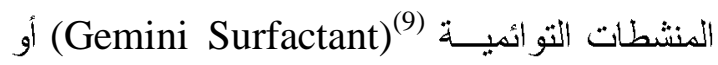
ما يعرف بجزيئة المنشط المضاعف وما لها لها من تأثير

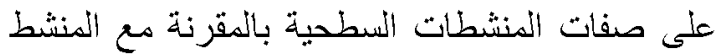

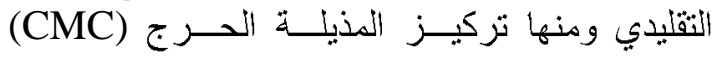
و الذوبانيـــ (Critical Micel Concentration)

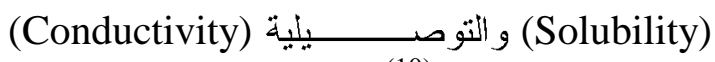

وغيرها من الصفات (10)

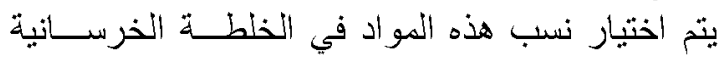

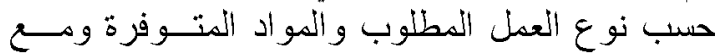

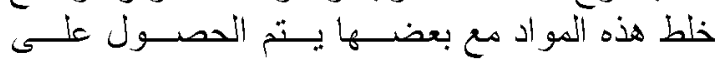

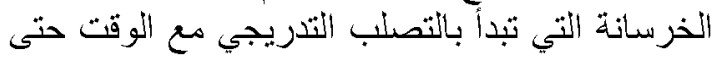

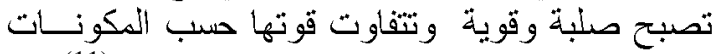

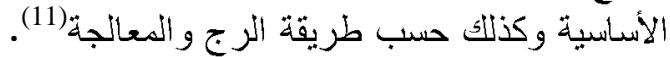

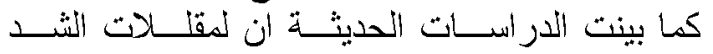

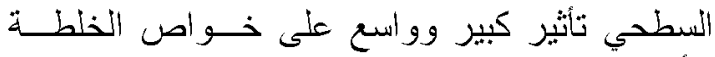

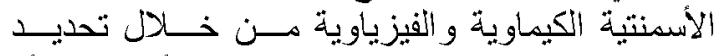

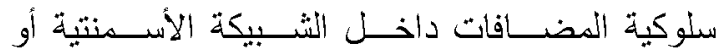

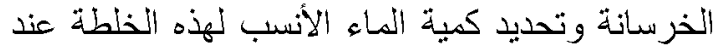

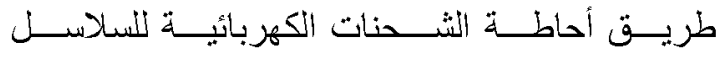

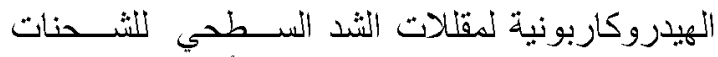

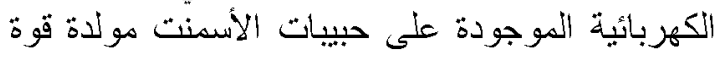

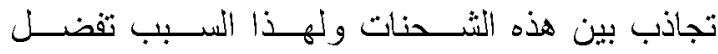

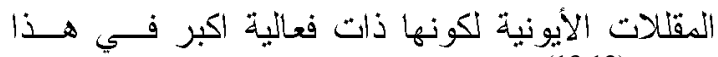

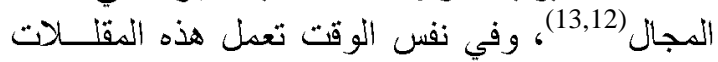

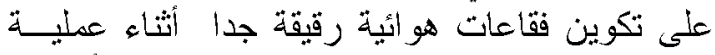

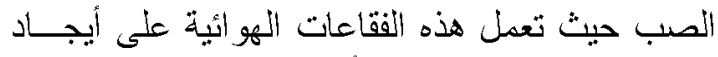

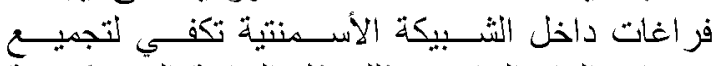

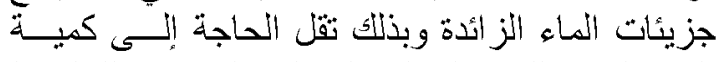

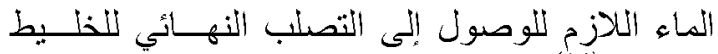

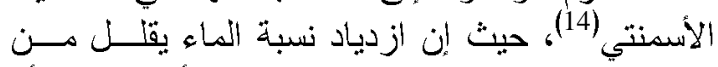

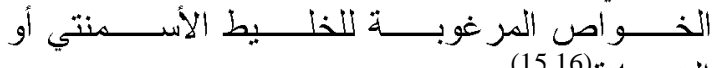
الخرسانة (15,16).

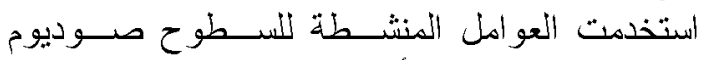

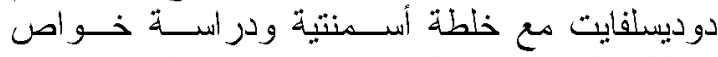

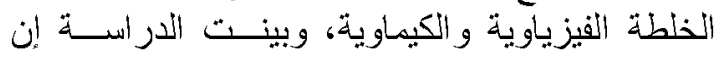

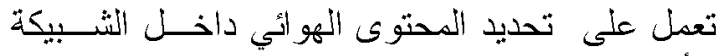

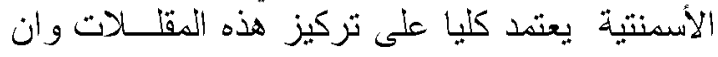

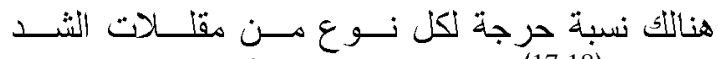

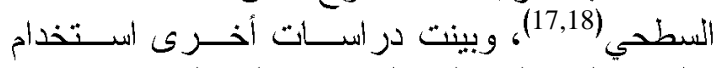

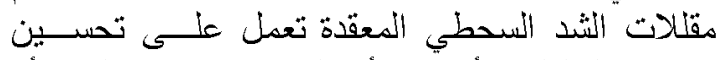

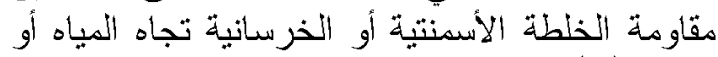

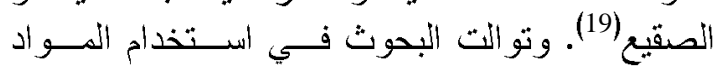

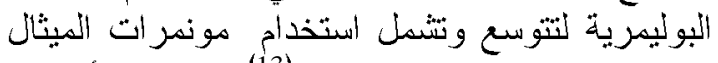
مثل اكريليت ومونمر الستايرين (13)، في حين أستخدم

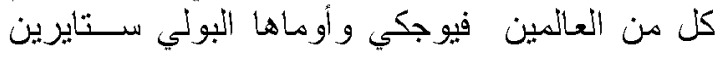

المقدمة:

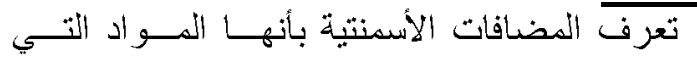

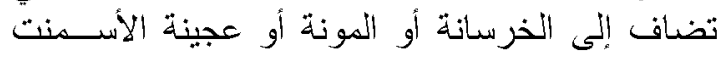

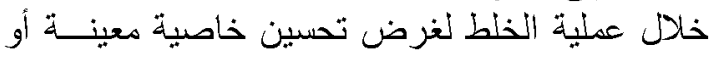

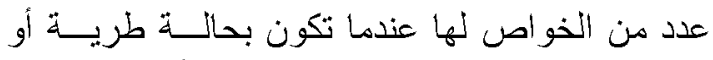

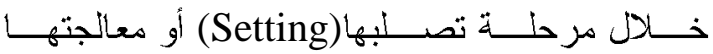
توان (Curing)

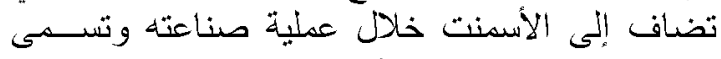

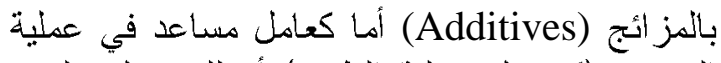

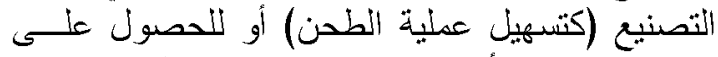

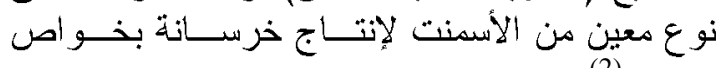

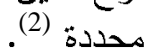

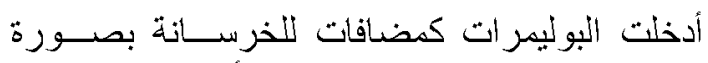

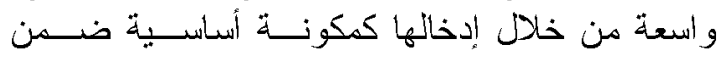

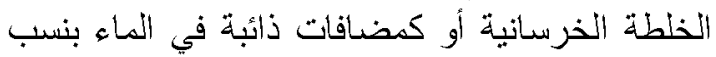

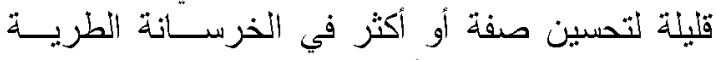
Fresh Concrete خرسانة، Hardened Concrete

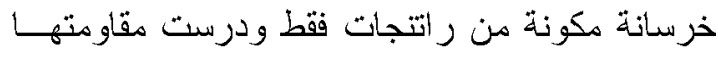

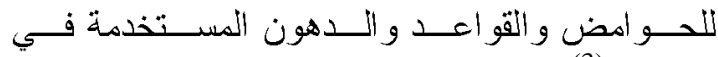

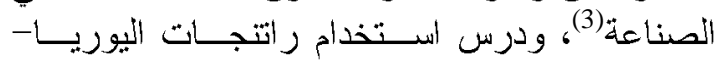

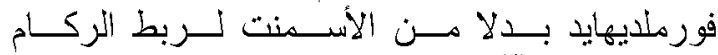
Aggregate

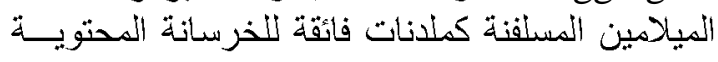

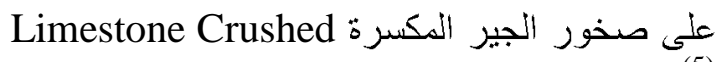

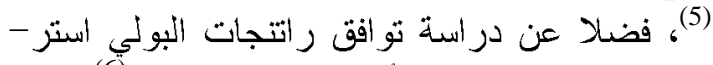

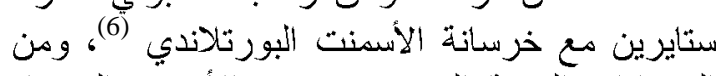

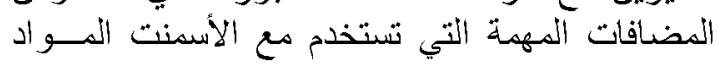

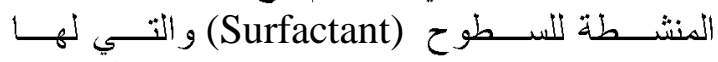

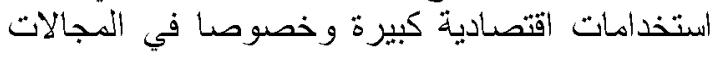
النفطية مثل كو اسر الاستحلاب (De-Emulsifiers)

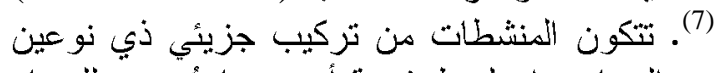

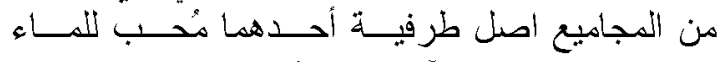

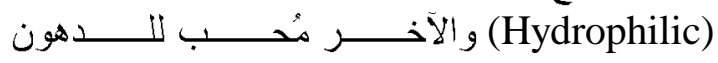
(Hydrophobic)

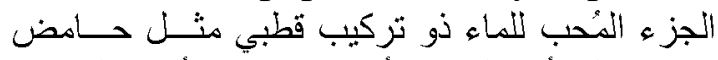

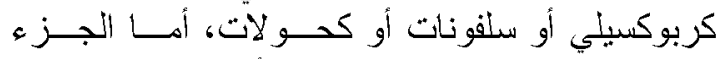

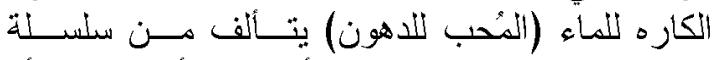
هيدروكاربونية اليفاتية طويلتة أو حلقية أو متفر عنة أو لون هيدروكاربونية النفاتية (8) هينة البئية

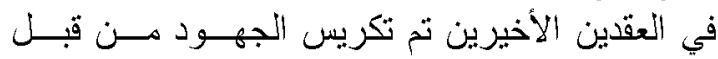

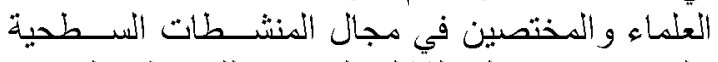

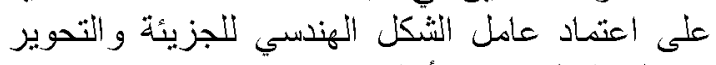

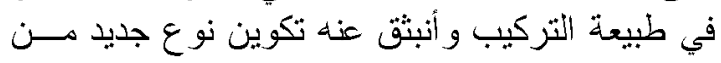




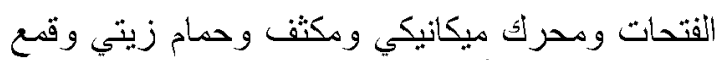

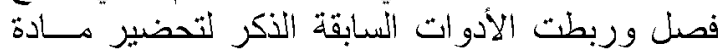
ذات ثابلية (Alkyl Benzene Sulphonic Acid)

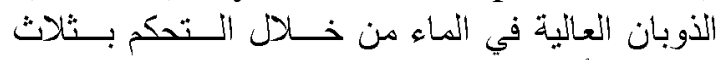

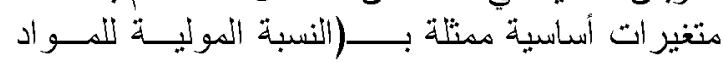

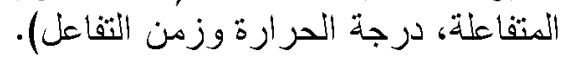

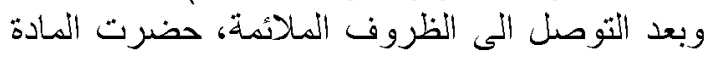
من تفاعل (Alkyl Benzene Sulphonic Acid) (Fuming , (Linear Alkyl Benzene (10g)) وذللك من خلال أضدافة

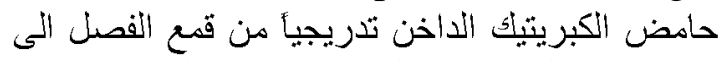

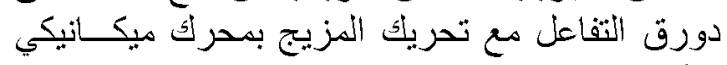

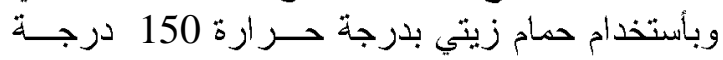

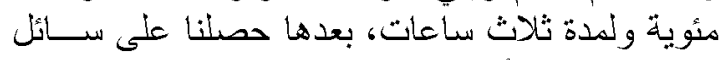

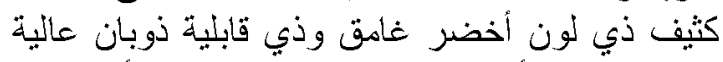

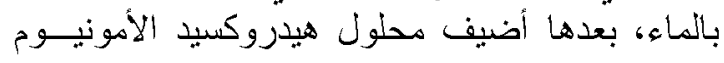

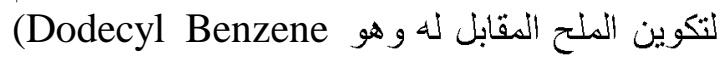
Ammonium Sulphonate)

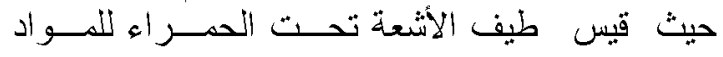

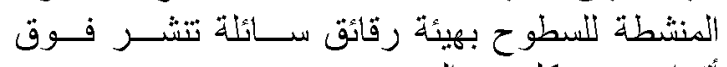

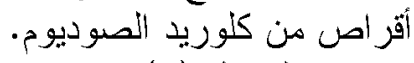

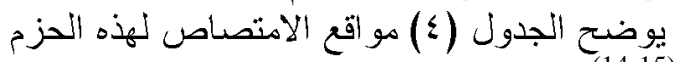

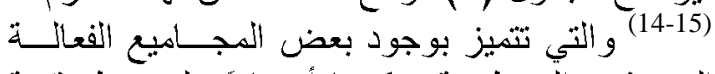

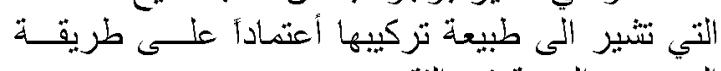
التحضير المبينة في الفقرة.

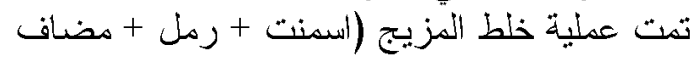

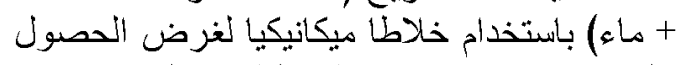
على مزيج متجانس بدرجة عالية من التجانس.

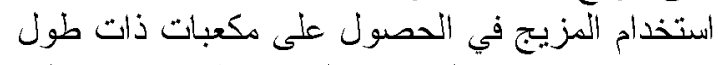

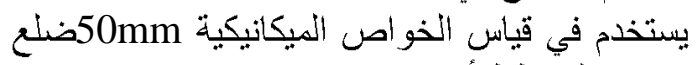
وحسب المخطط أدناه:

Filler + Cement + Sand + Water + Mixing for 5 minutes $=$ Surfactant Modified Iraqi Cement

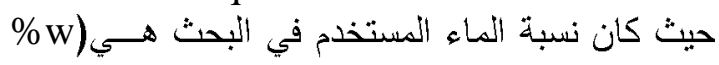

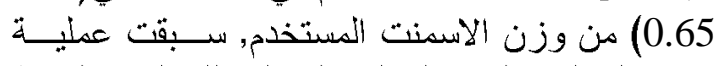

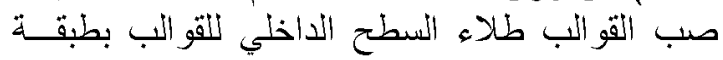

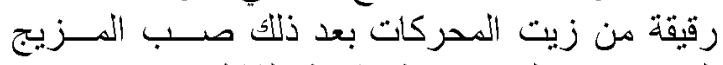

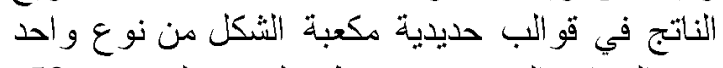

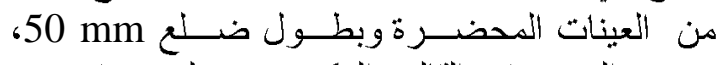

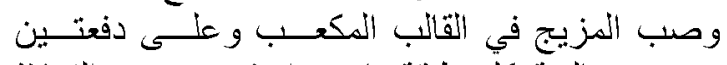

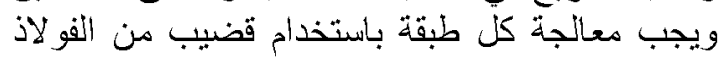

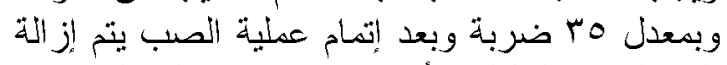

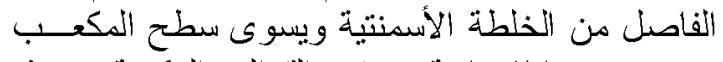

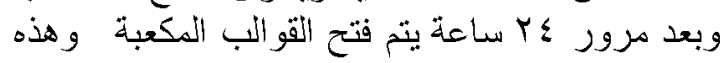

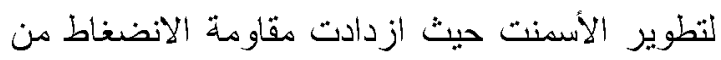

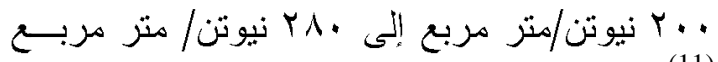

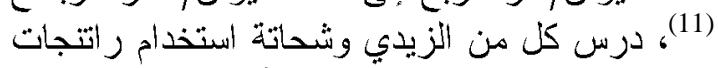

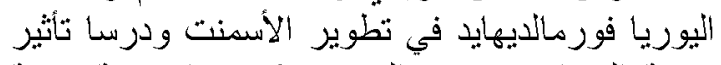

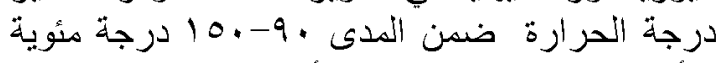

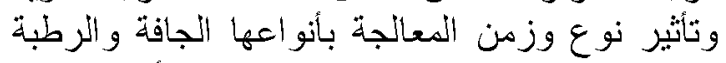

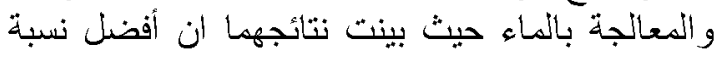

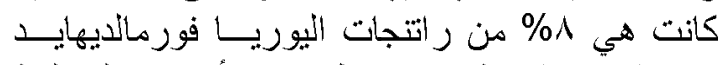

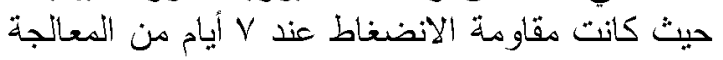

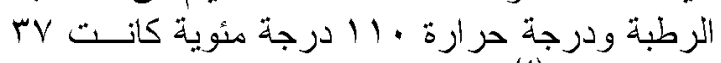

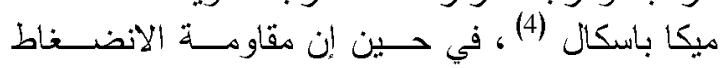

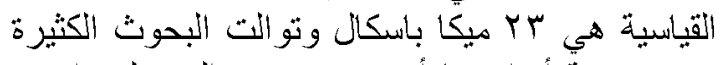

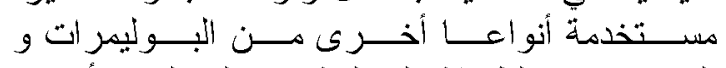
المضافات.ان لطريقة المعالجة بعد التصلب التصن الأبتدائي

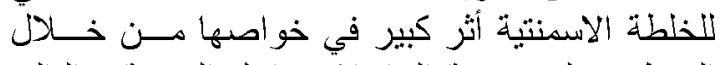

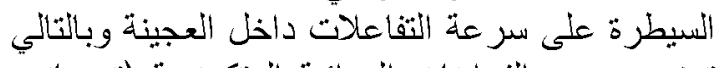

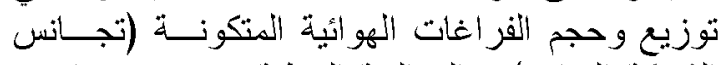

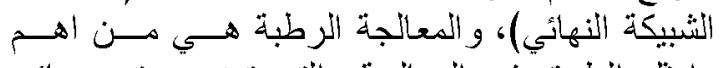

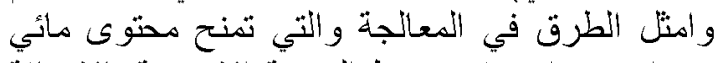

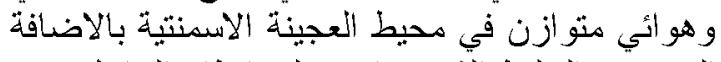

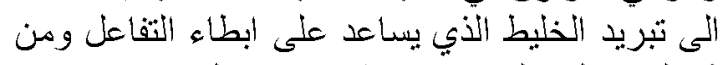

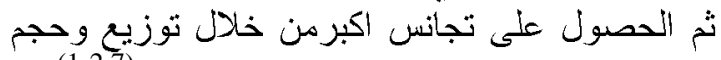

الفقاعات الهو ائية وبالتاني الفراني اغات الثبرن خلنيكية(1-2,7).

الجاتب العملى: البورتلاندي الأعتيادي و المنتج من قبل معدل أم قصر الأري

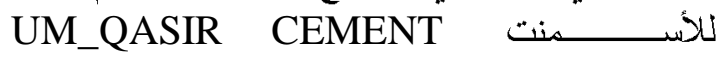

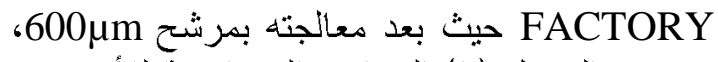

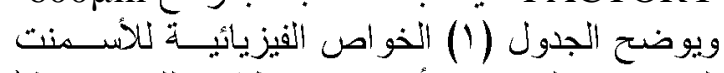

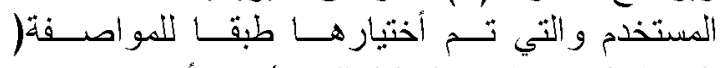

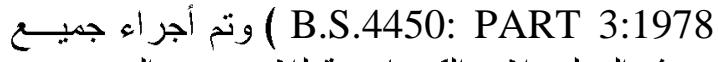

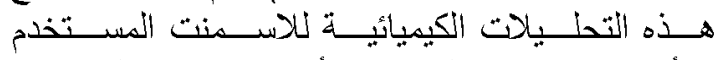

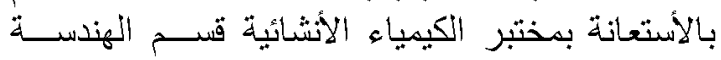

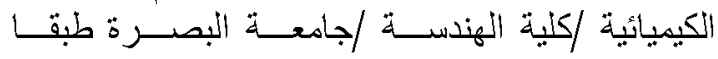
للمو اصفات التالية: (B.S.4450: PART 2:1972)

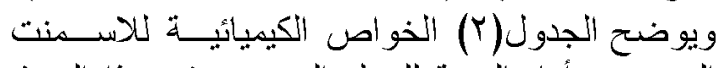

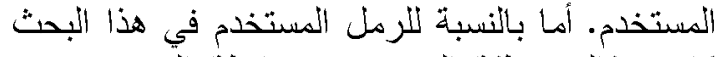

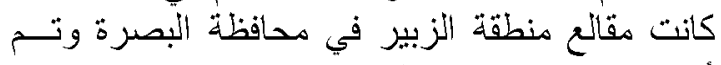

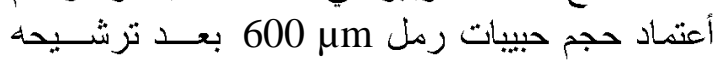

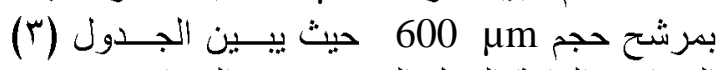
الخو اصل العامة الرمل المستخدم في البحث. تم في هذا البحث تحضير الكادة المنشطة للسطح (Dodecyl Benzene Ammonium بو اسطة أستخدم دورق كروي ثنلاثي Sulphonate) 
تبــ MARUTO TESTING MACHINE

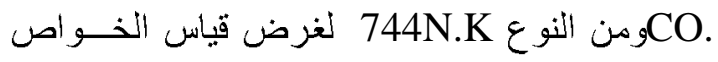

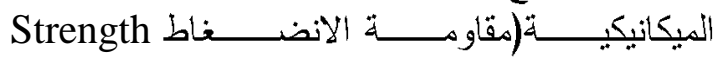
Compressive

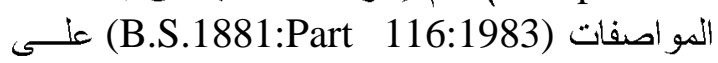

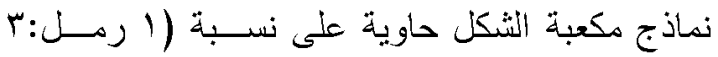

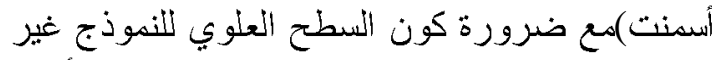

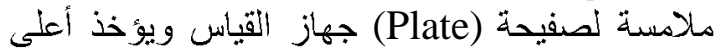

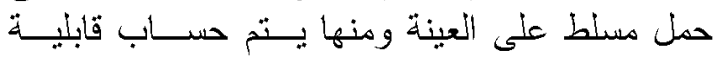

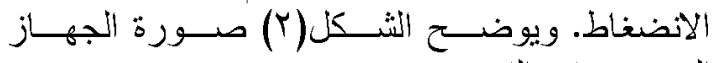
المستخدم في الفحص مصن

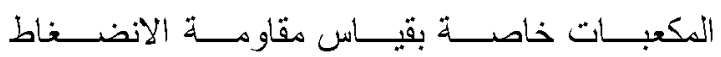
(1) (Compressive Strength) أثثكال القو الب المستخدمة في عملية التحضير • بعدها

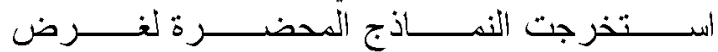

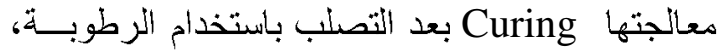
حيث توضع النماذج المعدة للقياس في قطعة صدئ صوفية

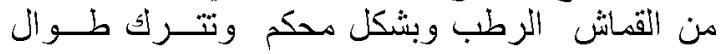

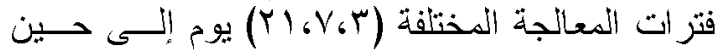

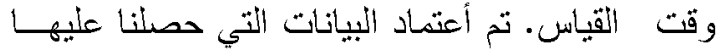

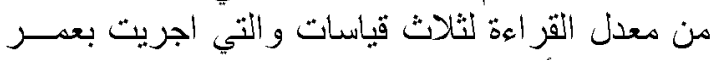

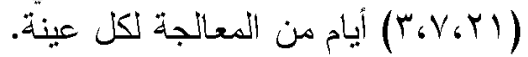

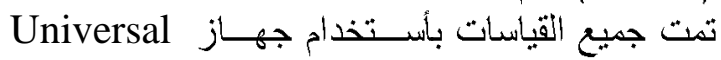
Compressive Testing Machine

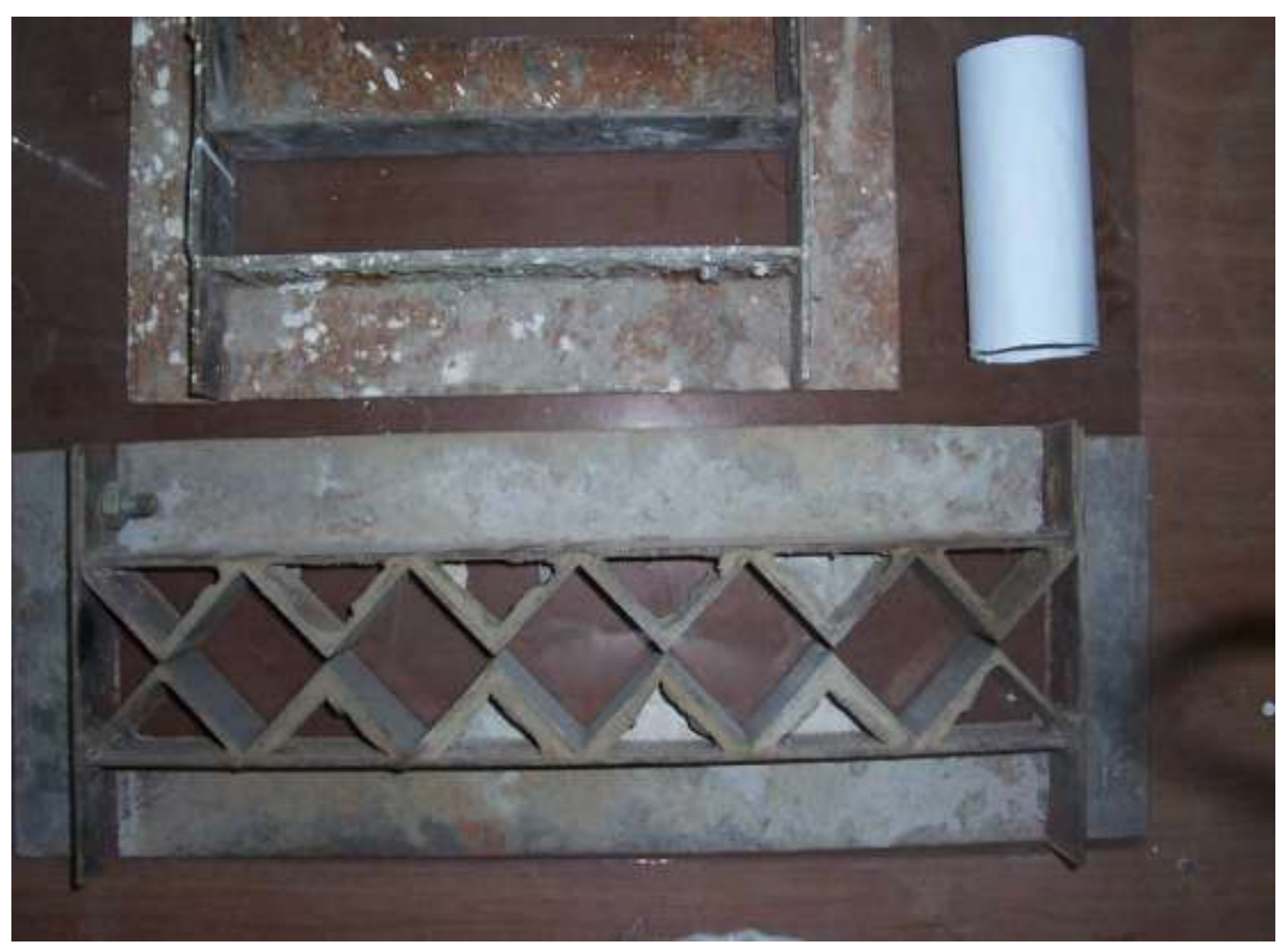

شكل (1): شكل القو الب الخاصة بقياسات مقاومة الاضضغاط. 


\section{ץ..人/ب

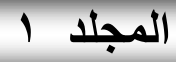

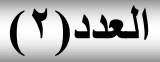 \\ مجلة علوم ذي قار}

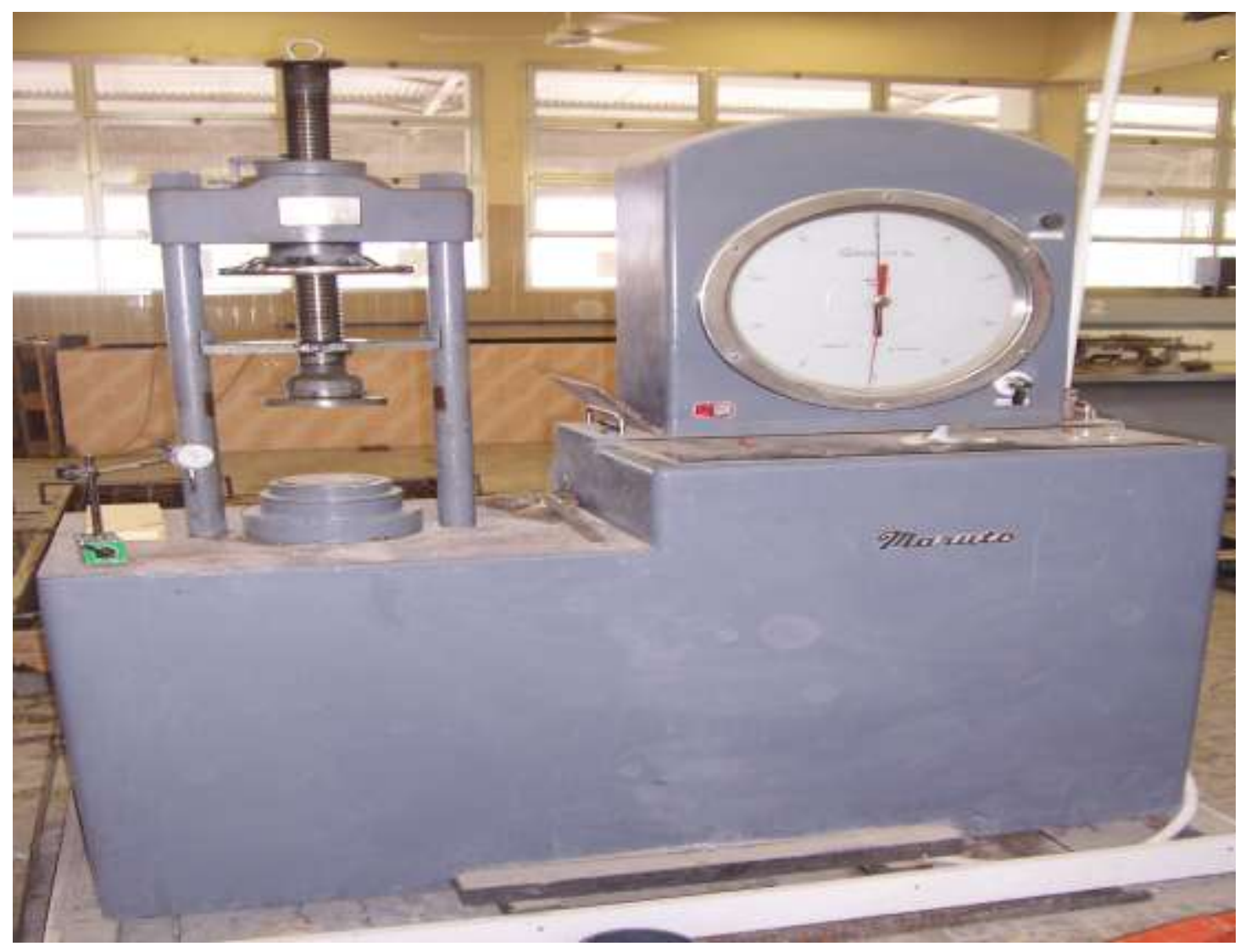

شكل (Y): جهاز قياس مقاومة الانضغاط.

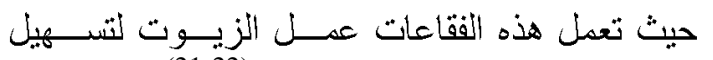
انزلاق محتويات الخلطة الإسمنتية (22-21.

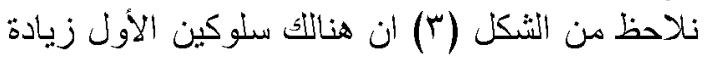

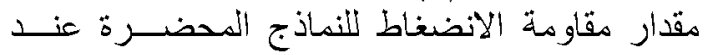

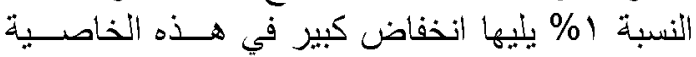
وبشكل و اضح عند زمني المعالجة ثلاثثة وسبعة أيام

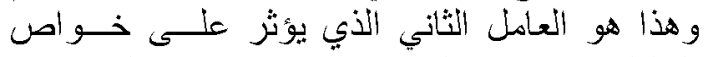

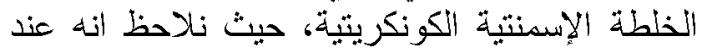

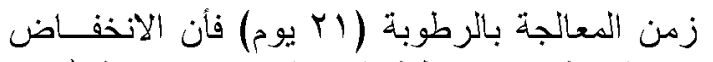
في مقاومة الانضغاطية يكون كبير الندا عند نسبة (وزن الانية

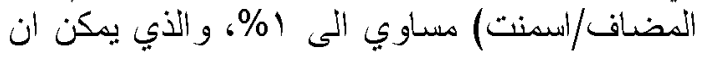

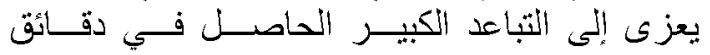

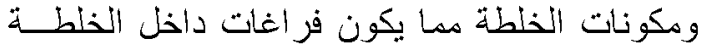
في حين إن زيادة نسبة المضاف و عند فترة المبات المعالجة

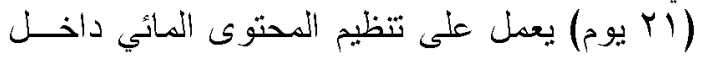

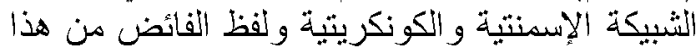

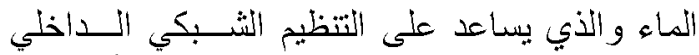

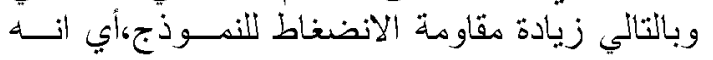
يعود إلّى حالة التو ازئ الحاصلة بين زيــادة نســبة
النتائج و المناقشتة:-

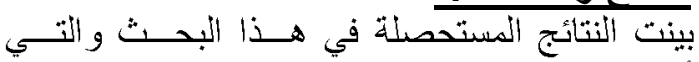

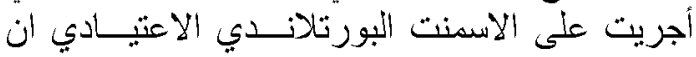
هناكت تأثير واضح اللمضافات على الخلطة الإنسنتية الإنية

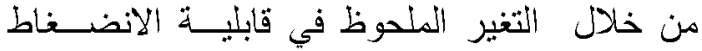

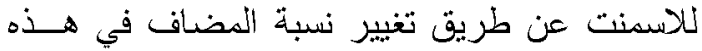
الدراسة (العوامل المنشطة للسطح) كما هو موضئ فئح في الثكل (r)، حيث يبين ارتباط هذه القابلية بشكل

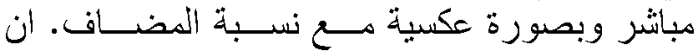

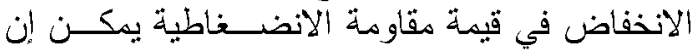

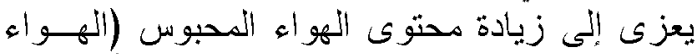

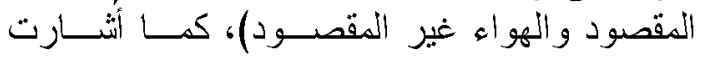

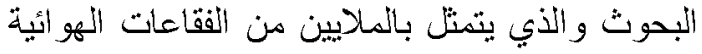

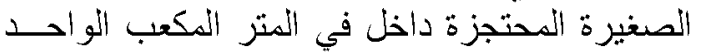

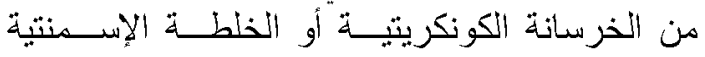

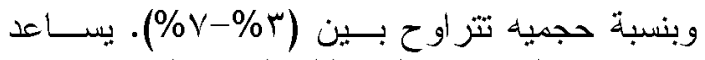
وجود هذه الفقاعات على تقليل ظاهرة النضوح حسبح زيادة خاصية التثنيل للخرسانة) (Work Ability) 
يمكن القول إجمالا ان إضــافة العوامـلـل التوأميــة

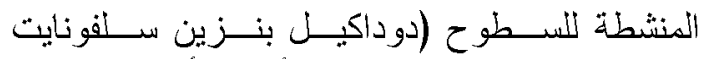

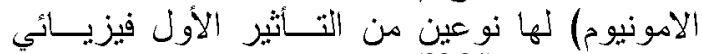
و الآخر كيميائي (23,24)، حيث يحدث الأول آنيا عند الأند

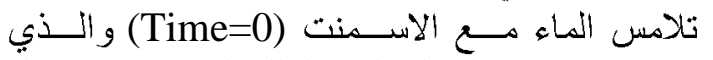

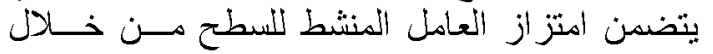

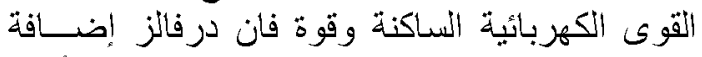

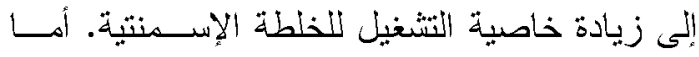

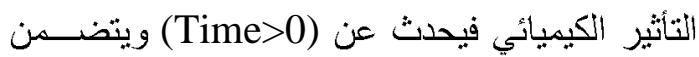

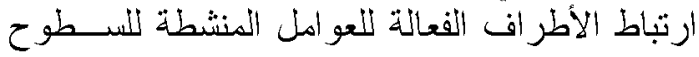

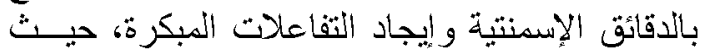

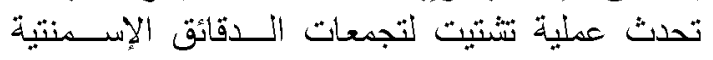

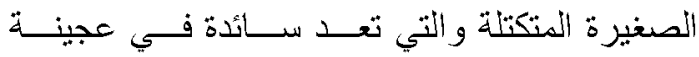

Conclusion -: الاستنتاجات

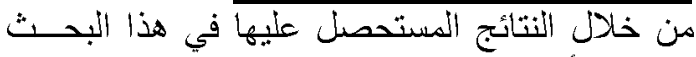

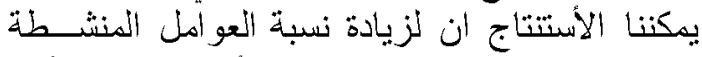

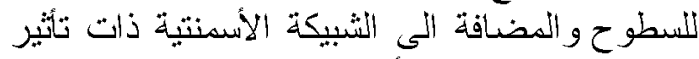

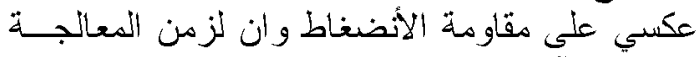

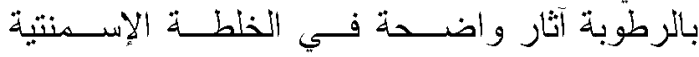

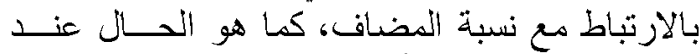

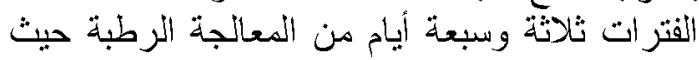
الزيادة في الخواص الميكانيكية للخلطة الإنـــنتية.

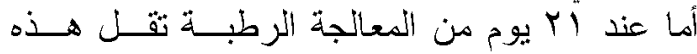

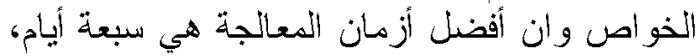

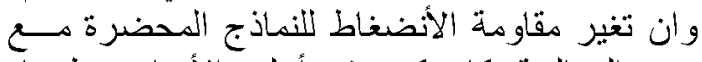
زمن الكعالجة يكاد يكون في أغلب الأحيان خطيسا،

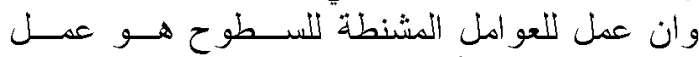

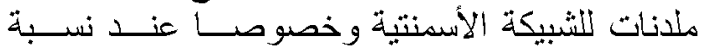

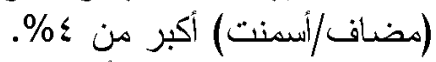

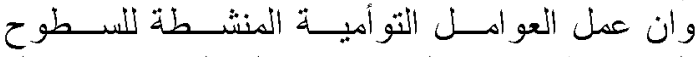

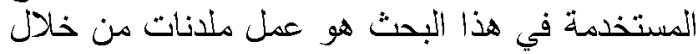

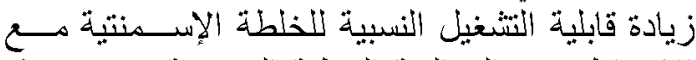

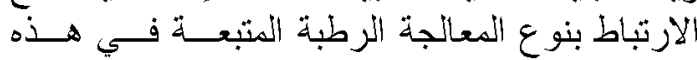

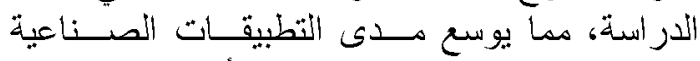

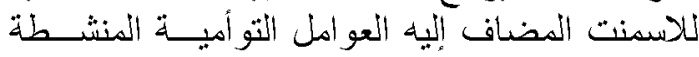
اللسطو ح.
العو امل المنشطة للسطح من جهـــة والــى زيــادة

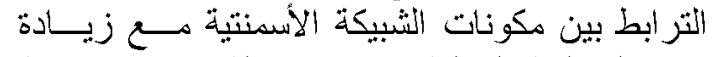

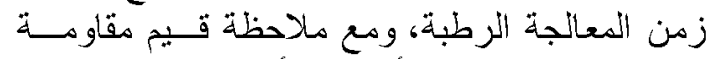

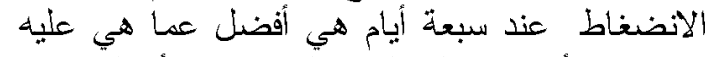

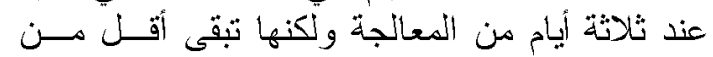

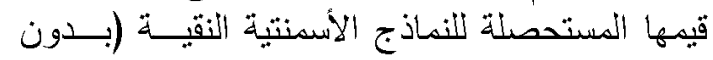

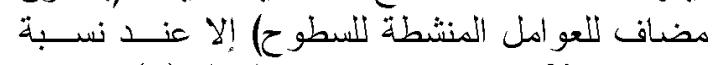

مضاف ؛ \% كما هو موضح في الثنكل (r).

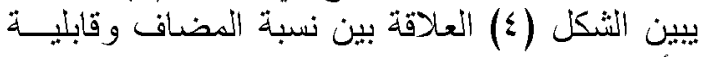

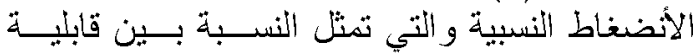

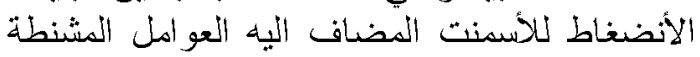

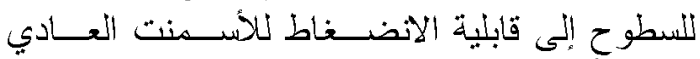

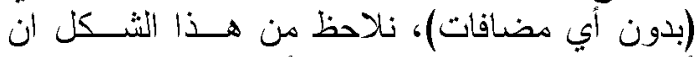

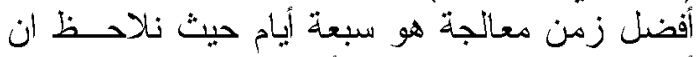

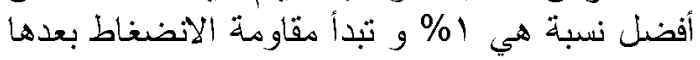

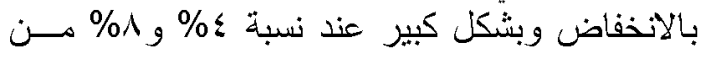

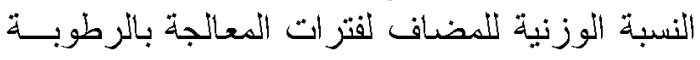

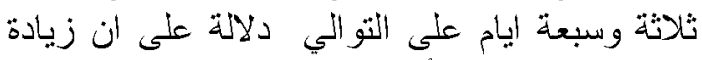

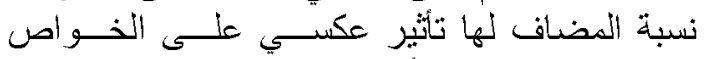
الميكانيكية للثبيكة الأسهنتية ناتج عن تباعد مكونات

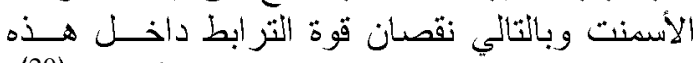

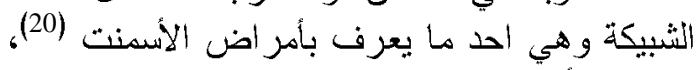

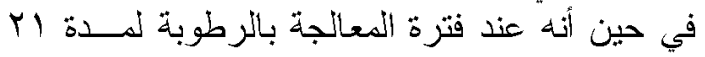

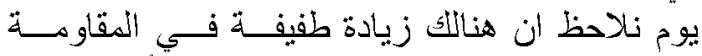

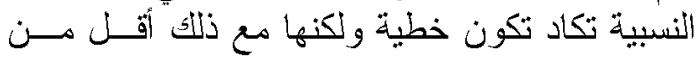
قيمتها عند الحالة النقية. نلاحظ في الثنكل (0) التنغير الحاصل في مقاومــة

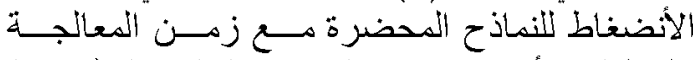

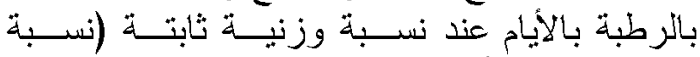

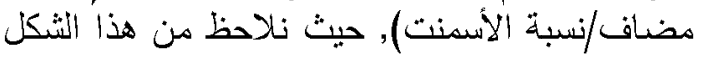

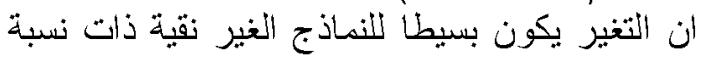

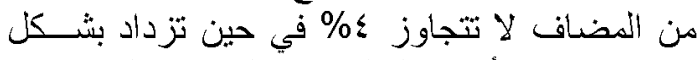

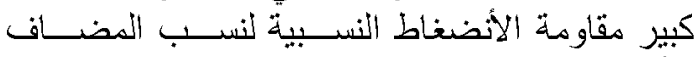

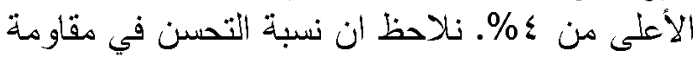

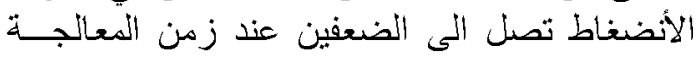

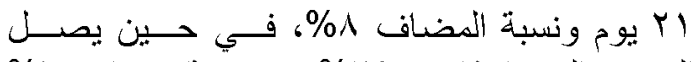

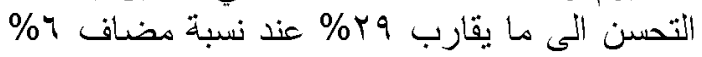

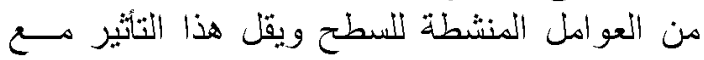

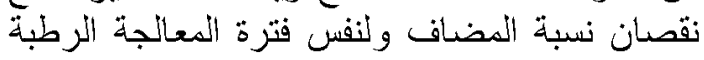

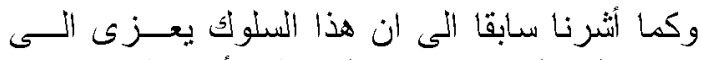
زيادة التقاعل بين دقائق الثبيكة الأسمنتية مع زيادة التهات

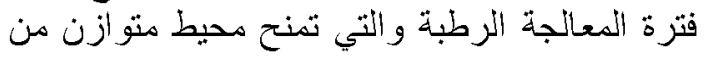

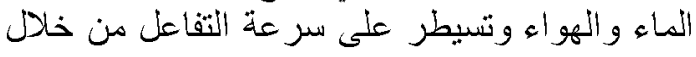

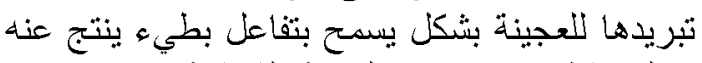
قو الب اكثر تجانس من الناحية الثبيكية. 


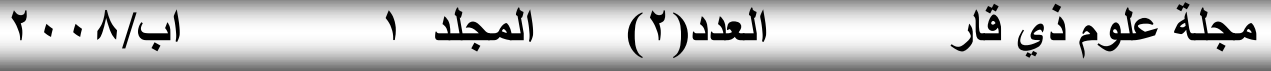

الجدول(1) الخو اص الفيزيائية للأسمنت المستخدم

\begin{tabular}{|c|c|c|}
\hline Property & Actual & Standard \\
\hline $\begin{array}{l}\text { Soundness } \\
\text { (Le chatelier expansion test) }\end{array}$ & $5 \mathrm{~mm}$ & $\leq 10 \mathrm{~mm}$ \\
\hline $\begin{array}{l}\text { Finenness } \\
\text { [Residue on B.S. sieve No. } 170(90 \mu \mathrm{m})]\end{array}$ & $7.1 \%$ & $\leq 10 \%$ \\
\hline $\begin{array}{l}\text { Setting time } \\
\text { I-Initial } \\
\text { II-Final }\end{array}$ & $\begin{array}{l}180(\mathrm{~min}) \\
250(\mathrm{~min})\end{array}$ & $\begin{array}{l}\geq 60 \mathrm{~min} \\
\leq 600 \mathrm{~min}\end{array}$ \\
\hline
\end{tabular}

الجدول(؟) الخو اص الكيميائية للاسمنت المستخذم

\begin{tabular}{|l|c|c|}
\hline \multicolumn{1}{|c|}{ Oxide } & Percentage & Standard \\
\hline Silica, $\mathrm{SiO}_{2}$ & 22.3 & \\
\hline Alumina, $\mathrm{Al}_{2} \mathrm{O}_{3}$ & 5.6 & \\
\hline Ferrie Oxide, $\mathrm{Fe}_{2} \mathrm{O}_{3}$ & 3.3 & \\
\hline Lime, $\mathrm{CaO}$ & 60.1 & \\
\hline Magnesia, MgO & 3.3 & $<4$ \\
\hline Sulfur Trioxide, $\mathrm{SO}_{3}$ & 1.6 & $<3$ \\
\hline Alkalis & 0.8 & \\
\hline Loss on lgnition & 1.4 & $<1.5$ \\
\hline Insoluble residue & 0.8 & $<1.5$ \\
\hline Total & 99.2 & \\
\hline
\end{tabular}

\begin{tabular}{|c|c|}
\hline \multicolumn{2}{|c|}{ الجدول (َّ) الخواص العامة الزمل المستخدم } \\
\hline Property & Sand \\
\hline $\begin{array}{l}\text { Specific gravity } \\
\text { a-Bulk } \\
\text { I-Oven dry } \\
\text { II-S.S.D } \\
\text { b-Apparent }\end{array}$ & $\begin{array}{l}2.62 \\
2.65 \\
2.75\end{array}$ \\
\hline $\begin{array}{l}\text { Water absorption (\%) } \\
(24 \mathrm{~h})\end{array}$ & 1.32 \\
\hline $\begin{array}{l}\text { Unit Weight }\left(\mathrm{Kg} / \mathrm{m}^{3}\right) \\
\text { a-Loose } \\
\text { b-Tamped }\end{array}$ & $\begin{array}{l}1662 \\
1751\end{array}$ \\
\hline
\end{tabular}




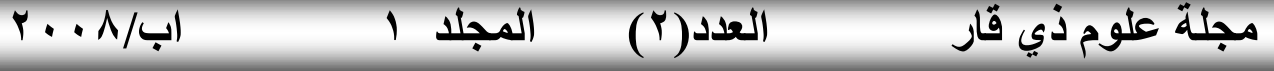

الجدول ( ) ): مواقع الامتصاص لحزم طيف الأشعة تحت الحمراء للمواد المنشطة للسطوح.

\begin{tabular}{|c|c|c|}
\hline نوع التذبئب & تذبذب المجموعة & العذد الموجي (cm-1) \\
\hline الثذبذب الأكساعي نمجموعة (C-H) & - NH & $3200-3033$ \\
\hline الثذيذب الأكساعي لمجاميع (C-H) & $\mathbf{C}-\mathbf{H}$ & $2960-2890$ \\
\hline الثذبذب الأشساعي لمجموعة (C=H) & & $1580-1600$ \\
\hline التذبذب الأحساعي لمجموعة الأمونيوم & $+\mathrm{NH}_{4}$ & 1409 \\
\hline التذبذب الأحثائسي لمجموعة NH & NH & 1064 \\
\hline التذبذب الأكساعي ثيز المنماثل نمجموعة & S-O & $1250-1220$ \\
\hline التئيذب الأكساعي شيز المنماثل نمجموعة & S-O & 1075 \\
\hline 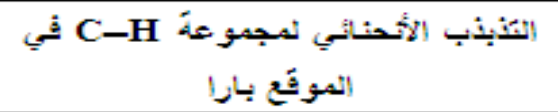 & & 834 \\
\hline 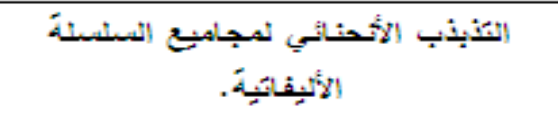 & $-\mathrm{CH}_{2}$ & 720 \\
\hline
\end{tabular}

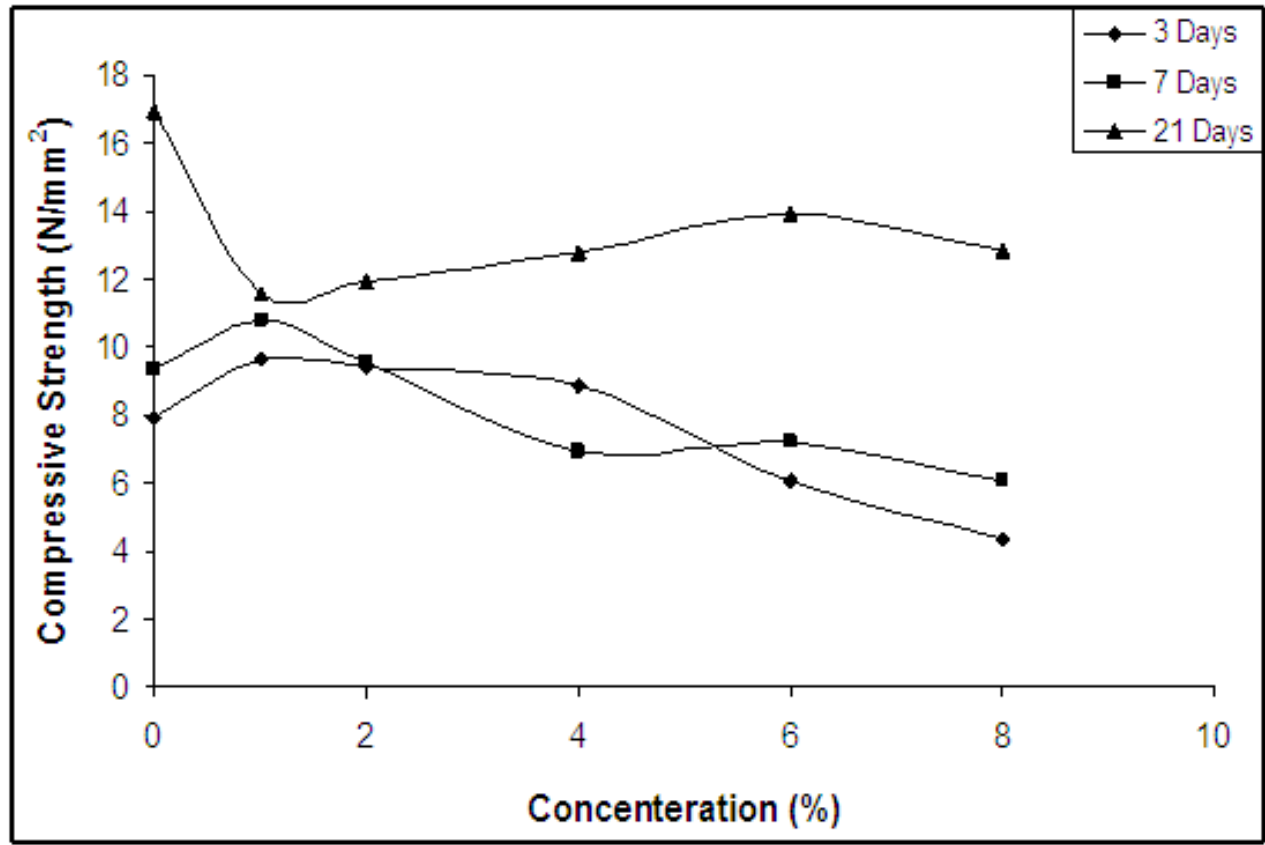

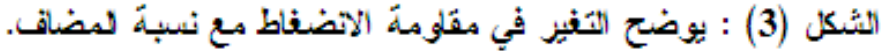




\section{| (ب/1) \\ العدد(ץ) المجلا \\ مجلة علوم ذي قار}

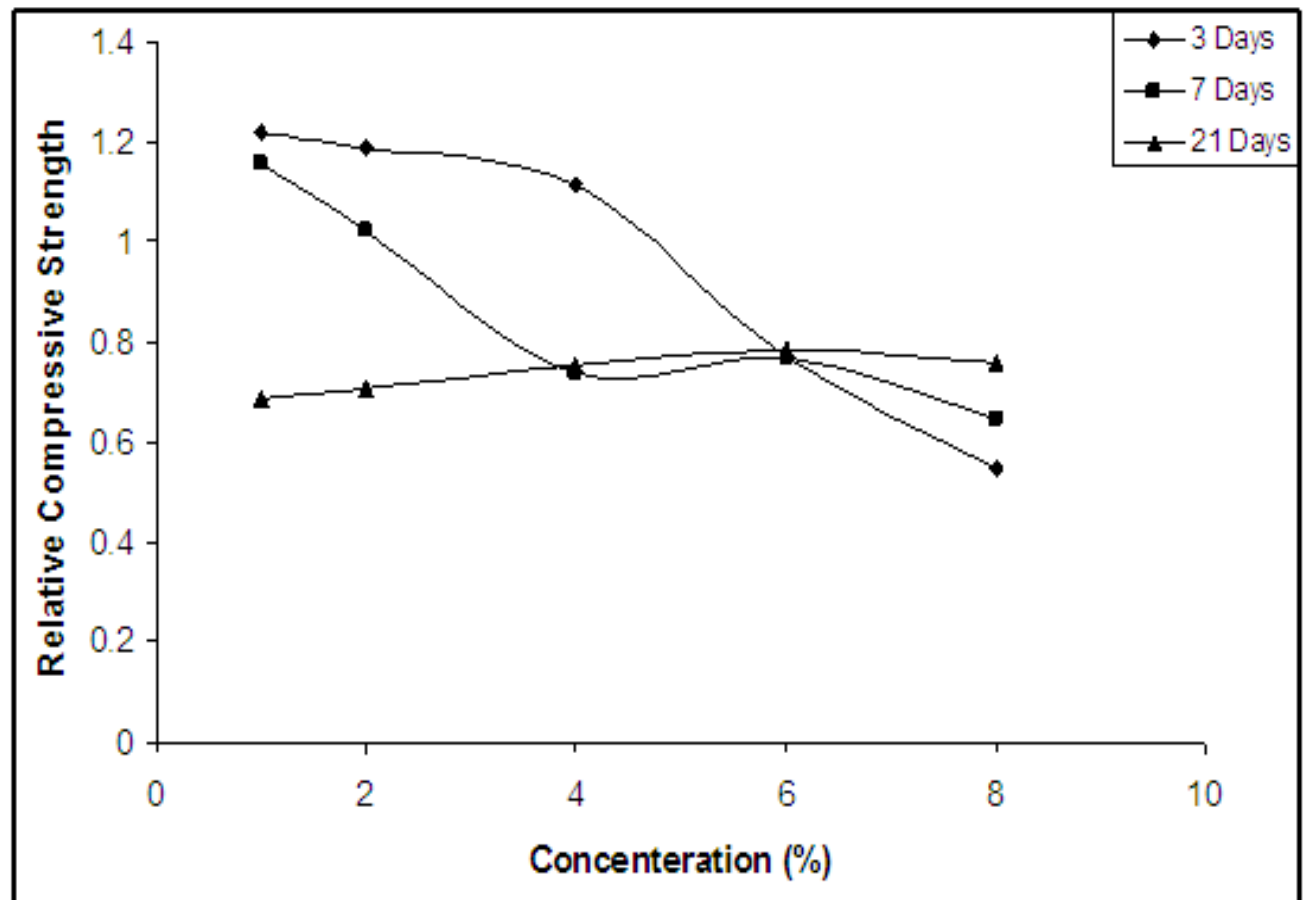

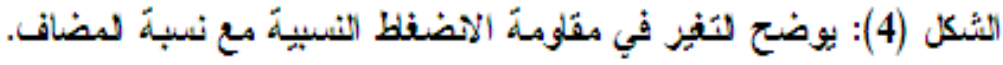

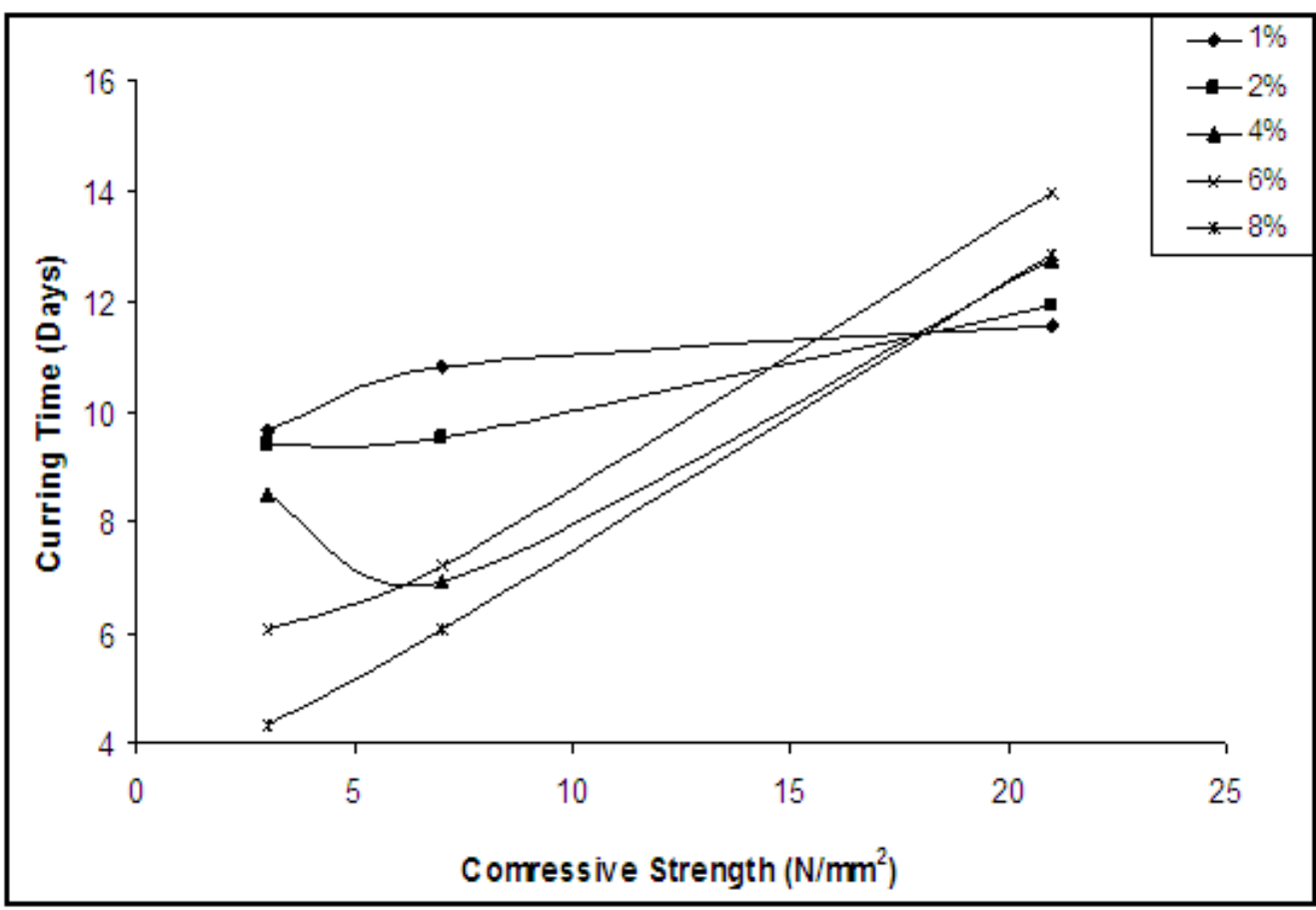

الثنكل (5): يوضح لتَفِز في مقلومة الانضفلط مع زمن لمعالجةَ بلزطوبة. 
Surface ", polymer in concrete, SP-58 ACI, p; 267-280.

15. T. Fuckuchi and Y. Ohama, (1979), "Process Technology and Properties of 2500 $\mathrm{kg} / \mathrm{cm}^{2} \quad$-Strength Polymer Impregnated Concrete", proc. of the second Int. congress on polymer in concrete, College of Eng., University of Texas at Austin, p;45-56.

16. A. Alzaydi, S. Shihata, (1990), "The Compressive Strength of a New Urea Formaldehyde-Based Polymer Concrete", J.f Material science, No.25, p;2851-2856.

17. M.L. Gambhir, (1986), "Concrete Technology",Tata Mc Graw-Hill Company. limited, New Delhi .

18. D.W. flower, (1983), "Polymer in Concrete", Hand book of structural concrete Mc. Graw - Hill , New York, p;8-10.

19. D. Hummel, (1968), "Identification and Analysis of Surface Activity Agents", London, $\mathrm{p} ; 5$.

20. V.M. Parikh, (1973), "Absorption Spectroscopy of Organic Molecules", London, 103.

21. ACI Committee 548, (1986), "Guide for The Use of Polymers in Concrete", (ACI 548. IR-86), ACI., Vol. 83, No.5.

22. I.M. Kamal, F.M. Falih and A. Ahmed, (2002), Iraqi J. Polymer, Vol.6,N.1, p;25-34.

23. CJolicoer and M.A. Simard, (1998),Cement and Concrete Composite,Vol.20, N.2, p;87101.

24. S.S Hodgson, (2000), "The Effect of Water/Cement Ratio and Air Entraining on Portland Cement Concrete Freez/ Thaw Durability", Internet Document,.

\section{References}

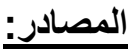

3. Anil Chadha, (2003), "Construction Chemicals-Admixtures for Concrete", CIDC, New Delhi.

4. Y. Ohama, T. Kobayashi, and K. Nawata,,(1986), The International J.of Cement Composites and Lightweight Concrete, Vol. 8,N.2,87-91.

5. A.A. Alzaydi, S.A. Shihata and T. Alp, (1990), J. of Materials Science, N.25,p: 2851-2856.

6. Q.P. Safa, ,(1992) "Effect of Superplasticizers on Properties and Structural Behavior of Concrete made With Abu-Ghar Crushed Limestone", M.Sc. Thesis Collage of Engineer, Civil Department, University of Basra.

7. N.O. Daniel and M. Saiidi, (1993), ACI Materials Journal,No.90-M8, p;59-67.

8. A.M. Neville, (1973), "properties of concrete", pitman publishing Ltd., U.K..

9. D.S. Shaw, "Introduction to Colloid and Surface Chemistry", Butter Worth, London, $2^{\text {nd }} E d,(1970) 206$.

10. F.MMenger,C.A.Littau,(1991),J.Am.Chem. Soc.,N. 113, p; 1451-1452.

11. M.J. Rosen, (1993), KHEMTECH, N.23, $\mathrm{p} ; 30-33$.

12. Gregory Garrick and M.S. candidate (2004) ME Graduate student conference .

13. J.A.Manson, (1981), "Overview on Current Research of Polymer Concrete, Material and Future Needs", SP69 on applications of polymer concrete ACI, p;1-7.

14. J.p.Hallin,, (1978), "Field Evaluation of Polymer Impregnation of New Bridge Deck 

اب/1) (
المجلد

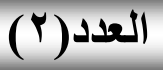
مجلة علوم ذي قار

\title{
The Effect of Adding (Dodecyl Benzene Ammonium Sulphonate) on the Compressive Strength Properties of the Cement.
}

\author{
Nadhim A.Abdullah \\ University of Basrah, Polymer Research Center, Department of Materials. \\ E-mail:Nadhim_2007@yahoo.com
}

\begin{abstract}
$\underline{\text { Abstract }}$
In this study we focused on adding (Dodecyl Benzene Ammonium Sulphonate) and this adding was in form of different ratio of these additive to the matrix of Iraqi cement (Om Quasar factory for cement). The prepared samples was in form of cubic and evaluated as they were treated with moisture treatment. All the prepared samples had a proportion of $(1 / \Gamma$ cement to sand) and in the form of cubes with aside $(50 \mathrm{~mm})$ long. The weight rate of (Dodecyl Benzene Ammonium Sulphonate) to the cement was (1\%-8\%). The obtained results showed that the cement mixture that had the weight rate of $2 \%$ at moisture curing is the best as it has good mechanical properties (compressive strength near to pure samples). Also this kind of surfactant have an opposite effect on mechanical properties and this effect is related to adding ratio and curing time. The effect of surfactant (Dodecyl Benzene Ammonium Sulphonate) works as plasticizer on cement matrix so the application range of used cement specially in oil well where these applications need flexible cement with high workability.
\end{abstract}

